\title{
Some Thoughts on Geological Surveying and Mapping Tech- nology and Development in the New Period
}

\section{Minghao Su}

Surveying and Mapping Brigade of Jiangxi Coalfield Geology Bureau, Nanchang, Jiangxi, 330001, China

\begin{abstract}
This paper first expounds the geological surveying and mapping technology in the new period, then discusses its application and development, and finally puts forward some suggestions to promote the development of geological mapping technology, hoping to provide effective reference for the relevant staff and the development of geological mapping technology in China.
\end{abstract}

\section{Keywords}

geological mapping; development; application

\section{新时期地质测绘技术和发展的几点思考}

苏明浩

江西省煤田地质局测绘大队，中国・江西 南昌 330001

\section{摘 要}

论文首先对新时期的地质测绘技术进行了阐述，然后从其应用、发展等方面进行了探讨，最后提出了几点促进地质测绘技术 发展的建议，希望为相关的工作人员以及中国地质测绘技术的发展提供有效参考。

\section{关键词}

地质测绘; 发展; 应用

\section{1 引言}

时代的发展进步在一定程度上促进和带动着行业的发 展, 任何行业都应当通过改革的方式进行优化完善, 当然地 质测绘技术也不例外。传统测绘技术受工作环境以及测绘设 备的综合影响，使得其测绘数据在精准度方面差强人意，步 入新时期之后传统测绘技术已经无法满足行业的发展需求， 因此加强对该种技术的改革创新已经势在必行。

传统的地质测绘技术不但精度低，并且消耗的人力、时 间较多。社会高新技术的发展, 为地质测绘技术的发展提供 了动力。目前现代测绘技术已经成为了地质测绘技术的主要 发展方向，下文对现代测绘技术的应用、发展，进行了相应 的分析、阐述。

\section{2 地质测绘技术发展概述}

传统的地质测绘行业完全仰仗着落后的经纬仪、平板仪 以及水准仪进行测绘作业，但是该种传统的工作模式致使许
多的高新技术无法有效及时的融入测绘行业, 长此以往必将 会使得行业发展陷入停滞的窘态局面。伴随着新时期的到来, 各种现代化的高端测绘技术逐渐的将 “老三仪” 取代，随之 而来的是以卫星导航定位技术、卫星遥感技术以及地理信息 系统技术等为主的现代新型测绘技术应用，而且上述技术正 在与时下的信息技术、电子计算机技术以及传感器技术等正 在趋于高度融合, 未来中国的地质测绘行业必将呈现出良好 的发展态势。

在地质勘查工作中，地质测绘是一项基础性前期性的工 作，地质测绘的质量和效率将直接关系到地质勘查整体工作 的顺利开展，例如测绘数据的精准度，就会直接影响到后期 岩石工程勘查、水文地质勘查等多工种项目的勘查质量与效 率。因此, 在地质勘查工作中, 为了更好地保证勘查质量和 效率, 就必须做好地质测绘工作, 确保测绘效率和测绘精度, 这对于保证地质勘查工作的顺利有效开展具有重要的意义。 在测绘工作开展过程中, 测绘人员主要是以地质理论作为基 
础，进而利用各种技术手段、设备仪器等对工程建设有关的 地质现象进行观测，进而将观测内容整合成地质条件的各个 要素, 在地形图上按照一定的比例尺绘制出来, 最终编制出 工程地质图, 为地质测绘工作中所应用的仪器设备 ${ }^{[1]}$ 。工程 地质图将对地质勘查工作起到尤为重要的指导作用。为了更 好地保证地质测绘工作质量, 就需要测绘人员在测绘过程中 尽可能地获取更多的地质信息, 对于工程施工现场的实际情 况进行深入的分析与了解, 准确的判断工程地下地质状况, 这样才能够为地质勘查工作提供有效的支持。在地质测绘工 作中应用先进地质测绘技术, 也能够更好地提高测绘质量和 效率。

\section{3 新时期地质测绘技术种类}

\section{1 遥感技术}

遥感技术是地质测绘中一种常用的探测技术, 其主要是 根据电磁波理论, 应用各种传感仪器对远距离目标的电磁波 信息进行收集和处理, 最后成像, 进而对地面被测目标进行 探测的一种技术，为遥感技术原理示意图。一般情况下，任 何物体都具有广谱特性, 他们都具有不同的吸收、反射、辐 射广谱的性能, 所以不同物体对不同频率的电磁波其感应也 有所不同, 这就是遥感技术的基础。在测绘工作中应用遥感 技术, 可以按照不同幅度反映出来的图像, 对地表的动态变 化进行分析, 进而了解工程地质的实际情况 ${ }^{[2]}$ 。应用遥感技 术还可以获得拟建项目不同比例的地图, 同时获得最新的影 像, 这也为地质勘查工作中实际测量工作提供了巨大的便利。 总结来说, 遥感技术具有测量范围大、可比性高、时效性强 的特点, 该项技术对提高地质测绘工作质量和效率具有重要 的作用。随着遥感技术的不断发展和进步, 新型传感器的研 制开发工作也在进行当中, 而多级空间分辨率影像序列的金 字塔也已经形成, 这对于提高遥感技术测绘整体水平具有重 要的意义。

\subsection{GPS 技术}

GPS 技术是 GlobalPositioningSystem 的简称, 即全球卫 星定位系统，该技术源于美国，最早用作于军事情报搜集以 及应急通讯, 随着该时间的推移, 各行各业都已经对其进行 了应用。GPS 技术主要是通过卫星, 对接收机的距离进行测量, 然后就能对其位置进行确定。该项技术为地质测绘工作提供 了新的发展方向。地质测绘工作具有工作周期长、工作强度
大的特点, 而 GPS 定位技术的应用, 有效降低了工作人员的 工作强度, 提高了其工作效率。GPS 技术对三维坐标的定位 不仅较为快速, 并且定位的准确度也较高, 同时还能对某一 个接收机的状态进行长时间监测。

随着 GPS 技术的发展, 在 GPS 技术的基础上, 衍生出 了RTK( 实时动态) 技术, RTK 技术不仅能够对目标点进行 快速、精准的测量, 并且还能结合第三方软件, 生成一次性 的电子地图, 这不仅提高了测绘人员的测量效率, 还极大程 度加快了制图的速度。RTK 技术的出现, 是测绘工作的一次 变革型的发展，为测绘技术的发展指明了新的方向。

\subsection{RS 技术}

$\mathrm{RS}$ 技术全称为（RemoteSensing 遥感技术），目前该技 术在地质测绘中已经得到了广泛的应用。RS 技术是一项基于 电磁感应的技术, 通过对地表的电磁波信息进行分析、处理、 传输, 进而就能对地表的各项事物进行远距离的测量、识别。 $\mathrm{RS}$ 技术和 GPS 技术相同, 其中主要的工具为 “卫星” 随着 $\mathrm{RS}$ 技术的发展，目前利用该技术已经能够动态化的反应地表 信息，这就为地质测绘工作提供了极大的便利 ${ }^{[3]}$ 。

\subsection{GIS 技术}

GIS 技术即地理信息系统, 也是地质测绘工作中一种常 用的地质测绘技术。近年来, 随着科学技术的不断发展和进步, GIS 技术水平也有了很大的提升, 现如今, GIS 技术逐渐朝 数据标准化、数据多维化、系统集成化、系统智能化的方向 发展, 这对于提高 GIS 技术的应用质量和效率也具有重要的 意义 ${ }^{[4]}$ 。将 GIS 技术应用到地质勘查工作中, 可以更好地保 证勘查质量和效率。

如 GIS 技术的集成平台是互操作地理信息系统，这一平 台能够将不同系统进行有效的连接, 确保不同系统之间信息 交流的通畅, 进而可以更加顺利快速地完成某个工程的测绘 工作。GIS 技术中有专门针对构件技术以及对象的系统, 能 够实现对地理信息系统模块的划分, 这样一来不同模块可以 负责相应的工作任务，最后进行集中处理，该技术对提高测 绘工作效率及质量具有重要的作用。

\section{$3.53 S$ 技术}

$3 \mathrm{~S}$ 技术并不是一个单独的技术，而是指的 GPS、GIS、 $\mathrm{RS}$ 三种技术的有机结合，通过这种方式能够将测量、信息处 理工作构成一个完整的有机体，如果将 RS、GPS 技术比作人 
类的眼睛, 那么 GIS 技术就相当于人类的大脑。3S技术的应用, 为测绘人员提供了一个完整的工作体系, “测量 - 整理数据 处理数据” 式的工作流程, 能全面优化地质测绘工作的工作 水平, 为地质测绘工作的发展提供了强有力的技术支撑 ${ }^{\left[{ }^{[}\right]}$。

\section{4 新时期测绘技术的应用情况}

\section{1 水利工程中的应用}

在水利工程中, 主要应用的是 $3 \mathrm{~S}$ 技术, 首先通过 $\mathrm{RS}$ 技 术对施工地区的水文情况进行检测, 然后结合施工地区的灾 害记录, 应用 GIS 技术对其数据进行分析, 进而为灾害的防 控措施的建立提供可靠数据。基于 $3 \mathrm{~S}$ 技术的测量方式，在对 施工现场进行检测的同时，也能够为 “水害” 的发生提供可 靠的预防情报, 避免水利工程建设盲目的进行 $\mathrm{H} 。 3 \mathrm{~S}$ 技术目 前不仅应用于水利工程的选址、现场调查, 在水利工程施工 的过程中也得到了广泛的应用, 借助 GPS、RS 技术测量的数 据, 然后构建出相应的水文模型, 借助 GIS 系统的数据统计、 分析功能, 就能为水利工程的开展、竣工验收提供可靠的参 考依据。另外, 借助 GPS、RS 技术所绘制的数字地图, 还能 为城市的排水管规划提供参考数据, 进而提升城市规划工作 的准确性以及工作效率。

\section{2 矿山测量中的应用}

中国地域辽阔, 所以矿产资源极为丰富, 在对矿产进行 开发利用的时候, 首先就要进行矿山测量, 而 GPS、RS 技术 就为矿山测量提供了强有力的支撑。GPS 技术主要用作对地 表的移动监测, 相关人员通过数据能够建立相应的控制网, 进而为中国矿产的开发提供保障。 RS 技术在矿山测量工作中 的应用时间较长, 该技术能够通过分析一定区域的电磁波数 据, 然后为矿区的保护、开发工作提供参考数据, 同时 RS 技术也有着辅助找矿的作用 ${ }^{[6]}$ 。

\section{3 生态监控中的应用}

通过 RS 技术的特性, 可以根据地表所反应的电磁波数 据, 分析出区域内植物的生长情况、分布情况, 然后应用 GIS 技术对这些数据进行分析, 进而就能对区域内的生态情 况进行更新, 通过 $3 \mathrm{~S}$ 技术的应用, 还能实现对区域内的生态 情况进行实时监控。目前现代测绘技术在湿地生态监控中应 用较为广泛, 湿地是中国生态系统中的重要组成部分, 目前 已经有诸多湿地被列为中国的生态保护区域。

\section{5 地质测绘技术发展的思考}

随着社会经济的快速发展, 对地质测绘工作需求也越来 越大, 而与此同时, 对地质测绘工作提出的要求也越来越高, 为了能够促进地质测绘技术得到更好的发展, 就必须加强地 质测绘技术的创新与改革。例如，在当前的新时期下，想要 促进地质测绘技术的快速发展, 就必须转变传统观念, 树立 其全新的地质测绘理念, 对测绘技术进行改进、优化、创新等, 以此来提高地质测绘技术水平。相关技术人员也应该不断地 拓宽思维, 例如, 要注重以开放、全面的思维去思考问题, 进而找出问题的原因, 最终采取有效的措施解决问题, 这对 于提高地质测绘技术水平也具有重要的意义 '在推动地质测 绘技术发展的同时, 还需要重视测绘工作领域和范围的扩展, 即将地质测绘技术的服务范围、应用范围进一步扩大, 使得 地质测绘技术在测绘工作中有更加广泛的应用, 发挥出更重 要的作用 ${ }^{[7]}$ 。这就需要技术人员不断地强化自身的专业知识、 专业技能, 同时还要加大对相关专业的研究力度, 如可以与 不同专业的技术人员进行有效的沟通、交流、探讨等, 加强 开发新技术、新功能, 以此来更好地提高地质测绘技术水平, 进而为地质测绘工作提供更加有力的保障。另外, 为了更好 地推动地质测绘技术的发展, 还需要加大人才培养的力度, 完备的人才储备是地质测绘技术发展的基础。

\section{6 新时期地质测绘技术未来发展建议}

\section{1 秉承勘测创新发展的原则}

当今世界是一个注重创新发展的时代, 科技创新发展应 当作为地质勘测行业的主要发展理念。通过对地质勘测行业 细致分析不难得知, 其中有诸多的层面可以作为创新发展的 切入点: 地质勘测技术工艺创新、地质勘测设备的创新以及 地质勘测行业运营体制等。通过地质勘测技术工艺的改革创 新, 不但能够提升工作效率降低工作成本, 而且还能显著的 提升侦测数据质量; 而相关勘测设备的更新换代, 也必然会 促使工作效率和工作质量水平显著的提升; 最后就是关于地 质勘测行业运营体制的改革创新，这种体制的改革创新一方 面可以帮助企业尽快摒弃传统的弊端管理模式, 而且还能引 导和督促整个企业朝着现代化的方向发展。

\section{2 加强地质勘测企业的管理工作}

受地质勘测行业的基本特点影响, 地质工作者的主要工 
作场景都现场一线, 而且分布范围既广泛又分散, 所以与之 相对应的管理工作难度系数相对较高, 如果没有一个科学系 统的管理机制为其保驾护航, 那么必然会对企业乃至整个行 业发展埋下不良隐患。因此, 相关企业和部门必须持续的对 地质勘测企业的管理工作进行优化改革, 具体的可以采取一 些任务分派制、岗位职责制、绩效考核制以及人才引进制等 多元化的新型管理机制, 以此来有效的加强内部管控, 最终 确保地质勘测行业能够健康有序发展 ${ }^{[8]}$ 。

\section{3 树立全新的科学性的地质勘测观念}

近年来, 受各种地质勘测新技术影响和冲击, 地质勘测 行业的传统模式和观念的统治地位遭到了严重的影响和冲击, 虽然地质勘测思维观念转变需要一段时间, 但是新观念取代 旧观念属于行业发展的必然之路 ${ }^{[9]}$ 。新时期国家相关部门以 及地质勘测领头企业，应当身先士卒发挥好良好的带头作用， 积极的贯彻实施各种新的措施, 尽快将实现思维转变, 根据 勘测项目的实际情况对工作方式进行改革创新, 以此来有效 的推动传统观念的解放和整个行业的快速发展。

\section{4 积极拓展地质勘测新领域}

现如今, 科学技术是第一生产力的理念已经在全球范围 内得到了普遍的认同, 因此地质勘测行业的发展进程中离不 开现代科学技术的有效运用。地质勘测行业若想要取得进一 步的发展进步, 那么就必须适时的引入各种先进的科学技术, 以此来持续提升或拓宽勘测技术水准和范围。

\section{5 及时解决地质勘测中出现的各种问题}

伴随着相关技术的不断改革创新及应用，地质勘测技术 必然会促使现代地质勘测行业的服务质量等级以及服务范围 不算的拓展延伸, 与此同时, 地质勘测行业面临的各种问题 也会更加复杂和严峻, 这些问题很多也都是传统工作经验中 很少涉及到的，因此相关的技术人员必须对此类问题予以高 度重视, 因为这既是地质勘测行业的发展难题, 同时也是提 升行业质量水平的有效途径。

\section{7 结语}

随着社会经济的快速发展, 中国各行各业的发展都得到 了有力的推动, 如工程建设行业、矿产行业等, 在此背景下, 社会对地质测绘工作的需求和要求也越来越高。而随着中国 科学技术的不断发展, 地质测绘技术水平也有了很大的提升, 其在地质测绘工作中发挥的作用越来越重要。如遥感技术、 全球卫星定位技术、地理信息技术等各项地质测绘技术都能 够有效的满足社会发展需要, 为各项地质测绘工作提供支持 与保证。为了更好地促进社会经济发展, 还需要不断地加强 地质测绘技术的研究和开发, 不断地提高地质测绘水平, 进 而更好地为地质测绘工作提供保障。

\section{参考文献}

[1] 常四海. 分析现代地质测绘技术及发展趋势应用探讨 [J]. 世界有 色金属, 2018(24):128-130.

[2] 吉木林. 地质测绘对于地质研究的重要意义探究 [J]. 世界有色金 属, 2018(15):39+41.

[3] 王永亮. 浅谈现代测绘技术在地质测绘中的应用 [J]. 工程建设与 设计, 2018(16):52-53.

[4] 刘铅. 测绘技术在地质勘查中的应用及发展方向浅析 [J]. 城市建 设理论研究 (电子版),2018(24): 100 .

[5] 陈思超. 论测绘地理信息技术在地质勘查工作中的应用发展 [J]. 江西建材, 2018(10):55+57.

[6] 蒋焕云. 地质测绘技术的应用及发展 [J]. 西部资源, 2018(02): 142143.

[7] 姚书磊, 马永芳. 新时期地质测绘技术及发展思考 [J]. 世界有色金 属, 2017(15):51+53.

$[8]$ 宋飞星, 武莉莉. 浅谈地质测绘工程中的测绘技术运用 [J]. 科技 风, 2016(01):171-172.

[9] 孙志鹏, 王文龙. 论现今地质测绘技术与发展 [J]. 价值工程, 2012 (15):56. 